\title{
85703 - SENSIBILIDADE PLANTAR DE IDOSAS COM DIAGNÓSTICO DE DOENÇAS OSTEOARTICULARES
}

\author{
Pôster - Gerontologia
}

Cátia Trennepohl / Trennepohl, C. / UNIJUì; Cristina Thum / Thum, C. / UNICRUZ; Dinara Hansen Costa / Costa, D. H. / UNICRUZ

Introdução: Doenças osteoarticulares propiciam desequilíbrios posturais, assim compreender as alterações de sensibilidade plantar em idosos com doenças osteoarticulares e fundamental na prevenção de maiores agravos ao equilíbrio. Objetivo: Descrever as alterações de sensibilidade plantar em idosas com diagnóstico de doenças osteoarticulares. Métodos: Trata-se de estudo observacional, descritivo e quantitativo, com idosas da comunidade diagnosticadas com doenças osteoarticulares. A coleta de dados ocorreu de janeiro a fevereiro de 2018, no munícipio de Panambi-RS, através de questionário sobre dados de saúde. A sensibilidade plantar foi avaliada através estesiômetro Semmes-Weintein, em nove regiões plantares e registrado o primeiro monofilamento sentido em cada local plantar. A análise estatística foi feita através de frequências absolutas e relativas, média e desvio padrão. O estudo foi aprovado pelo Comitê de Ética em Pesquisa da Universidade de Cruz Alta nํㅜ 2.386.155 e todas idosas assinaram o Termo de Consentimento Livre e Esclarecido. Resultados: participaram da pesquisa 11 idosas, com idade média de $70(\mathrm{DP} \pm 4,86)$ anos, todas com diagnóstico de artrite e/ou artrose. O local mais acometido foram os joelhos, com 7 (63,6\%) idosas. Relataram dor nos membros inferiores, 10 (90,9\%) idosas. A prática de exercícios físicos foi mencionada por $4(36,4 \%)$ idosas, enquanto que $9(81,8 \%)$ afirmaram não ter sofrido queda(s) no último ano. Na análise da sensibilidade plantar do pé direito, $4(36,4 \%)$ idosas apresentavam diminuição da sensibilidade em todas as regiões avaliadas. No pé esquerdo, 7 (63,6\%) participantes mostraram perda sensitiva em todas os locais plantar. A região com maior perda de sensibilidade plantar foi o calcâneo, no qual todas idosas apresentaram perda sensitiva. Conclusões: portanto a prática de exercícios físicos é necessária em idosos com doenças osteoarticulares, seja para atenuar a sintomatologia, como para prevenir perdas funcionais. O calcâneo mostrou-se como a região com maior redução da sensibilidade plantar, assim como o pé esquerdo, demonstrando a importância de intensificar a atenção aos idosos com doenças osteoarticulares, pois a associação desta patologia e a diminuição da sensibilidade plantar inerente ao envelhecimento podem prejudicar o controle postural e propiciar maior risco de quedas.

Palavras-chave: Envelhecimento. Idoso. Fisioterapia. Artrite. Pé. 